\title{
Les pratiques artistiques dans l'apprentissage des langues. Témoignages, enjeux, perspectives, LIDIL special issue, ed. by Filippo Fonio and Monica Masperi, 52/2015 ; Approcci teatrali nella didattica delle lingue. Parola, corpo, creazione, LEND special issue, ed. by Filippo Fonio and Monica Masperi, 45/2016
}

\section{Francesco Bonelli (Université Grenoble Alpes)}

The special issues of the journals LIDIL (2015) and LEND (2016), edited by Filippo Fonio and Monica Masperi (Université Grenoble Alpes), give a welcome contribution to the field of foreign language learning through drama and the arts. These two volumes are the result of a common research project, carried out by the co-editors since 2012, within the organisation in Grenoble of the conference Les pratiques théâtrales dans l'apprentissage des langues: institutionnalisation et enjeux de formation au niveau européen. As the co-editors assert in both introductions, the main aim of the research project was to put together various experiences and reflections, originating from different academic contexts and countries, in order to answer to the following crucial questions concerning foreign language teaching and learning through dramaand arts-based approaches (LIDIL 6-7, LEND 9):

a) What role can the performing arts and drama-based activities play in secondary school and academic courses?

b) In what forms may they be introduced and taught?

c) How can such practices be integrated into courses and curricula for foreign language students?

d) What connection can be established between these practices and CEFR's action-oriented approach?

e) How can we overcome the suspicion often raised in certain institutional contexts of these didactic methods? And by what means would it be possible to manage recurrent problems in their application, such as lack of resources, logistical constraints, pupil numbers, reconfiguration of teacherlearner relationship, confusion about assessment, risk of marginalisation of the aesthetic and literary text in learning supports?

In responding to those questions, particular attention has been paid to reports of experiences from French-speaking contexts (France of course, but 
also Quebec that is very well represented). Nevertheless, we can also find essays from other countries (Italy, Colombia), languages and cultures (German, Arabic, English). The target of the cases proposed to the reader is broad and spans from primary to secondary school courses up to academic curricula.

The first issue (LEND) is divided into two sections: the first contains articles that focus on certain theoretical issues, while the second is principally devoted to reports of practical experiences in the field.

The reflection on the role of such approaches in educational institutions is developed, first of all, in terms of texts chosen by the teachers. This is what the author Rollinat-Levasseur does in her contribution on the FLE dramatic repertories around the world in both scholarly and academic circles. As the author highlights, the choice of a text for its staging within a theatre-oriented situation is not only a linguistic matter, but it tells us something about the representation of the target language that the teachers have and transmit to their students. Moreover, other variables, such as the audience's expected reactions and participation, also have to be taken into account.

In both sections a great emphasis is given by most authors to the role of the assessment in L2 courses, which integrate the performing arts or drama activities. This topic often goes hand in hand with the need to adapt and revise the scale of CEFR descriptors to such pedagogical approaches. In this respect, questions often arise concerning what type of competencies should be assessed and how assessment could take the CEFR grid into account. On the basis of Jouvet's works and the classical rhetorical notion of delivery, Fabienne Dumontet proposes, for example, to rethink the assessment criteria in the light of the concept of mediation. As a competence involved at different levels - interlinguistic, transmodal - in both drama-based activities and the CEFR approach, mediation would well represent a common ground for redescribing categories, such as proficiency or other language skills. From a complementary perspective, Berdal-Masuy and Renard tend, instead, to reform the CEFR descriptors taking into account the importance of body as an effective communication tool in the target language. An updated CEFR grid is thus proposed that shows how assessment can be "embodied" when learners are holistically considered as "beings".

This redefinition of CEFR descriptors obviously implies a comparison between learners and actors, on a theoretical level. Ollivier develops this reflection at the beginning of the issue by tending towards Bakhtin's concept of dialogism, Benveniste's theory of énonciation and Stanislavski's and Strasberg's definitions of actor. More specifically, he builds a didactical model in which the insertion of theatre-tasks enables to combine linguistic, communicative and cultural objectives, as well as to rethink on the role of learners, on the basis of a concept of the teaching-learning process as a co-construction. Seeking for new parameters in this matter can also mean to directly involve students in their own assessment, which is what Cocton points out regarding the FLE classes with a drama-based approach. If in such courses the traditional assessment often proves to be inadequate, a solution - the author suggests - could be to 
involve learners and encourage a reflective approach to emerge in them. Such contributions show to what extent a serious work on CEFR descriptors is needed in order to place drama- and arts-based foreign language learning within a more stable institutional framework. In this sense, assessment problems are crucial and can't be avoided beforehand.

This issue brings us to another important focus of this volume, i.e. the role and place of drama- and arts-based approaches in the academic context or secondary school. A stunning example of how these practices may find an institutional recognition is given by Gray, whose contribution is focused on the use of drama in the Masters programme for students preparing for the CAPES (one of the examinations that are compulsory to become a teacher in France). In particular, Gray convincingly demonstrates that an adapted use of certain drama-techniques in oral expression classes can successfully address some of the requirements for the CAPES oral exams, such as awareness of oral communication, appropriate use of the voice and other extra-linguistic factors. Always with reference to the role that drama and arts may have in teachers' training is the contribution by Dubois and Tremblay, which describes an inventory of the situation of the French teaching through drama in Canadian classrooms.

The second issue (LIDIL) is structured into two parts (contributi and esperienze) and collects 11 articles revolving around various applications of drama and the performing practices. Assessment issues are also central in this second volume and are tackled by different points of view and strategies in many of the contributions (Hinglais and Pouyé; Potapushka-Delfosse; Duchêne), with a particular emphasis on concepts like learners' awareness and the self-assessment process.

This volume is also based on the distinction between drama and theatre approaches. In the drama category an example can be given by the article by Hinglais and Pouyé, who discuss about the benefits of using artistic mediation in the specific context of the Municipal Courses of the City of Paris, with a significant intercultural outcome. Another example can be given by the essay by Capron-Capuozzo, who tells about her experience in a pilot project for students of a professional high-school in Valle d'Aosta, where the application of drama techniques was aimed at representing the experience of difference and strangeness in the context of a debate on immigration and on the development of transversal skills, such as empathy and creativity. Always with reference to the drama approach, the contribution by Privas-Breauté should also be highlighted as it clearly demonstrates how drama-based activities can be successfully introduced and applied also in apparently distant sectors, such as professionalising courses for students in English Business Management: an important step forward in an unexplored territory that shows how the performing arts certainly have an high potential also beyond their 'traditional' application in arts or literature courses.

Other contributions, instead, tend more towards a theatre-oriented approach (Duchêne) or propose an accurate combination of both approaches (Foisil). 
Among these, of particular interest is the paper by Nanni and Al-Addous concerning a theatre workshop on the learning of Arabic, which was staged at the School of Translation and Interpreting of Forlì. Community theatre experiences like this one clearly show that staging an L2 or bilingual production (in this case, Arabic and Italian), in fact, goes beyond mere linguistic objectives and may represent an extraordinary means to explore history and cultural themes of the target language.

Finally, a special mention should be given to two other main interests of this second volume: first, the attention paid to body and holistic or embodied learning, as is the case of Tummillo's paper, which is focused on the role of gesture in foreign language learning, not only by a semiotic point of view, but also as an instrument to help memorisation among students. Or the contribution by Potapushkina-Delfosse, which explores the place that the body can have in teaching English for theatre in elementary school courses. Second, the importance that many teachers attribute to multimedia translation or multimediality in their experiences. Terzuoli shows, for example, how certain drama-techniques, such as improvisation or sketches, can be very helpful to 'translate' and make literary texts in the target language more approachable to students. De Serres's contribution proposes, instead, to use games as pedagogical tool and analyses the experience of creating the board game Coup de théâtre to help students to learn French idiomatic expressions. Furthermore, drama and transmodalisation are also at the core of the contribution by Amireault, Silva Ochoa, Lacelle and Trottet concerning the concept and realisation of a didactical platform for the dramatisation of Quebec's folk tales (TCLQ) in the French foreign or second language class.

The two volumes certainly represent a major contribution to the field of drama- and arts-based practices in foreign language learning for the variety of approaches and perspectives faced. They fill the bibliographical gap that concerns the French-speaking context and, at the same time, offer reports of contributions and experiences that are perfectly transposable also to other languages and contexts. Moreover, this double work has the great merit to develop a serious reflection concerning the assessment criteria and redefinition of CEFR's descriptors, which is unprecedented, to the best of my knowledge. In this respect, I believe these special issues constitute not only a first important step for a better integration of drama, theatre and the performing arts within scholarly or academic courses, but also a great chance for renewing the debate concerning assessment beyond the boundaries of foreign language, literature or theatre courses. 